\title{
Dissecting the drivers of rural demographic decline: the case of the New England \& North West region of New South Wales
}

\author{
Neil Argent University of New England \\ Email: nargent@une.edu.au. Address: Department of Geography and Planning, University of New \\ England, Armidale, NSW, 2351, Australia \\ Paper received 21 September 2021; accepted 14 November 2021; published 29 November 2021
}

\begin{abstract}
Background

In the contemporary academic literature, rural population decline has generally been regarded as a long-running and almost natural phenomenon.
\end{abstract}

\section{Aims}

This paper examines the complex temporal, spatial and cultural dynamics of the population of an inland, largely agriculturally-dependent rural region, the New South Wales New England \& North West Statistical Division (SD), from the late 1990s to the 2016 Census. It investigates the key demographic processes that have driven the region's spatially and temporally-uneven experiences of population change - including decline - over this tumultuous period, using these as portents of the regional population's likely future trajectories.

\section{Data and methods}

The analysis draws on Australian Bureau of Statistics Census data for the SD's population as a whole, and for the non-Indigenous and Indigenous segments of the population.

\section{Results}

The analysis identifies that a profound ageing process is underway across the entire region, is becoming more severe with the passing years, and leading to natural decrease for some Shires. However, the SD's Indigenous population presents a striking contrast to the non-indigenous one, growing rapidly, increasing its share of the population and is a force for demographic rejuvenation.

\section{Conclusions}

The analysis reveals that a profound ageing process is underway across the entire SD and is becoming more severe with the passing years. The SD's Indigenous population presents a striking contrast to the non-Indigenous, growing rapidly, increasing its share of the population - particularly in the western-most LGAs - and is a force for demographic rejuvenation.

\section{Key words}

New England \& North West region; Indigenous populations; rural population ageing; natural decrease. 


\section{Introduction}

Not long ago, the idea of 'rural decline' was something of a tautology; during the 1980s, 1990s and into the 2000s the two terms almost pre-supposed each other. The era of the 'rural crisis' triggered enormous media interest in and coverage of, inter alia, the dire struggle of family farmers against international commodity markets and national banks, dying country towns, disappearing public and private services and sporting and social clubs, along with the fate of those residents left behind to cope. Academic interest in 'the plight of the bush' was indicated by a number of key publications seeking to disentangle the myriad causes of the crisis from its effects, and to offer policy-relevant remedies (see, for example, Pritchard \& McManus 2000; Gray \& Lawrence 2001). Australian rural regions were not alone in experiencing the chill winds of economic and political restructuring, with similar processes of restructuring noted in the US, Canada, the UK and numerous European nations where neoliberalised political reforms to macro-economic management in general, and to agricultural industry in particular, combined to pressure rural regions and towns (see, for example, Ramsey 2010; Nelson 2001; Bryant \& Joseph 2001; Ilbery \& Bowler 1998).

From a demographic perspective, the phenomenon of rural population decline in the contemporary era is neither surprising nor especially newsworthy. Ravenstein's laws of migration and the hypothesis of the mobility transition (Zelinsky 1971) - the latter providing the missing migration and spatial dimension of the theory of demographic transition - foresaw the tendency for societies become more urbanised as they undergo modernisation under the conditions of industrial capitalism. The relative growth of the world's urban population at the expense of rural areas has continued since the onset of the Industrial Revolution and, by 2005, the global population had become, for the first time in recorded history, predominantly urban (United Nations 2012). However, such a finding tells us little, if anything about the complex ways in which rural regions and places are changing around the world. Due to their own particular initial resource endowments, politicaleconomic and institutional histories, different rural areas will have their own unique experience of economic, technological, political and demographic change.

In this paper, I examine the complex temporal, spatial and cultural dynamics of the population of an inland, largely agriculturally-dependent rural region, the New England \& North West region of New South Wales, from the late 1990s to the 2016 Census. The paper seeks to tease out the key demographic processes that have driven the region's spatially and temporally-uneven experiences of population change - including decline - over this tumultuous period, using these as portents of the regional population's likely future trajectories. Notably, the paper explores these processes and trajectories for the region's population as a whole, then for the non-Indigenous and Indigenous segments, though the comparative analysis is constrained somewhat by a lack of local demographic data for the Indigenous population.

\section{Rural population decline in the literature}

In the contemporary academic literature, rural population decline has generally been regarded as a long-running and almost natural phenomenon that commenced from the end of the famed postWWII "long boom". Often, decline is associated with the increasing mechanisation of agriculture, associated expanded economies of scale in farming, and concomitant increasing pressures on the 
family farming system that prevailed across much of the developed world. Such accounts give primacy to economic forces in explaining the push factors for demographic change, i.e., for people to leave rural employment and hence rural areas altogether. Levels of urbanisation across the globe increased throughout the post-WWII era, although they were already high in so-called metrocentric settler societies such as Australia, New Zealand and Canada by the 1950s (Smailes et al. 2019; Argent 2016).

The fortunes of agriculture and of rural society and settlement have generally been intimately intertwined with one another but also bound up with the institutions of government and subject, to a greater or lesser degree, to their political objectives. In Australia, colonial and then Federal and State Governments from the 1850s to the 1980s explicitly and actively encouraged rural versus urban economic, demographic and social development via "closer settlement" policies and a swathe of support mechanisms for agriculture and rural living (Williams 1975; Argent 2002), a stance consistent with the so-called productivist regime that pertained across Western Europe, the UK and North America (Ilbery \& Wilson 1998; Wilson 2001). Nonetheless, while productivist supports for farming were thought to be a tide that lifts all boats (read individual farmers and rural regions) population trends painted a slightly more complex picture. Rural population trajectories across much of the socalled 'Global North' have been anything but homogenous over the past few generations with, for example, net population loss through the 1950s to 1970s across Western Europe and the United States coinciding with slow growth in Australia but relatively robust net increase in the UK (Argent 2016).

Subsequent international trends are similarly heterogenous in spite of the generally widespread occurrence of so-called counterurbanisation (a.k.a. the population turnaround) during the 1970s and 1980s (Beale 1975; Hugo 1994). In some nations such as Australia, counterurbanisation did indeed have a measurable impact for a decade or so on destination regions and towns almost across the rural spectrum, but then became more spatially and socially selective, and tied much more to higher amenity regions (Argent et al. 2007). As noted in the literature, peri-metropolitan fringe zones, coastal, lacustrine and riverine settings, and well-watered and well-connected inland regions have been favoured by a new generation of counterurbanisation migrants (Burnley \& Murphy 2004). Elsewhere, a range of population pathways have been documented, depending somewhat on local economic bases, land uses and relative accessibility/remoteness.

Counterurbanisation migration flows bolstered the population stocks of select rural regions but growing concern was expressed for the more remote, natural resource dependent and 'deep rural' (Lowe \& Ward 2009) regions of Europe, North America and Australasia. In tacit recognition of the interrelated nature of rural populations, land use and economy (see Brown \& Argent 2016), a 'desertification' phenomenon was observed, where net population loss and demographic decline (e.g., loss of young cohorts, 'left behind' aged people) combined with public and private service withdrawals to effectively eviscerate the demographic, social and economic life of more remote regions and villages (Cawley 1994; Sorensen 1990).

Consistent with a Myrdalian perspective on capitalist regional development, in which cycles of circular and cumulative causation drive regional divergence, " $(i) n$ many cases, demographic change is taken as a proxy indicator for regional performance, and hence population decline is equated with weak economic development and/or less attractive living conditions" (Dax \& Fischer 2018 p. 301). 
For those regions and localities not favoured by amenity-led in-migration and counterubanisation flows, then, local economic dependence on natural resources - particularly agriculture but also mineral and energy extraction - can generate demographic responses (e.g., age-specific outmigration) that further drive down factor conditions for the local economy. A corollary of these processes is the marginalisation of the 'left-behind' - those ageing-in place, the relatively immobile due to physical incapacity and/or lack of access to reliable transport - constrained in their ability to access even basic public services as these retreat to localities further up the local urban hierarchy, and unable to liquidate their housing asset and move to a better location due to the collapse of the local housing market (Cawley 1994).

\section{Diverging demographic dynamics in an agriculturally-dependent region}

\subsection{Overview of the New England \& North West region}

The empirical focus of this paper is the broad Northern Statistical Division (SD) of New South Wales, an official spatial unit that comprises the Northern Tablelands, North Central Plain and North West Slopes subregions (see Figure 1). The region was re-named the New England and North West region in 2011, and for simplicity's sake is referred to as New England \& North West hereafter. Covering an expanse of approximately 99,100 square kilometres (Australian Bureau of Agricultural and Resource Economics and Sciences 2015) in the northern sector of the state, the SD's centroid is an approximate six hour drive north of the State's capital, Sydney, and five hours drive south from the Queensland capital, Brisbane. As discussed elsewhere (Argent et al. 2010), a good understanding of the region's historical geography cannot be had without recognising: (1) the process of colonisation (or invasion, as the Indigenous inhabitants and others would see it), and (2) the particular role that the region fulfilled in the colony's (later the State's) and the nation's development as a supplier of vital food and fibre and export income. In relation to the first point, the Indigenous peoples of the area - principally the Anaiwan and the Kamilaroi - knew the Tablelands well and it is they who felt the full force of the extension of pastoralism into the region from the $1830 \mathrm{~s}$.

A squatting 'mode of occupance' (Holmes 2006) developed in the region, facilitated by environmental conditions, locational and regulatory factors and the technological limits to settlement. Population densities and overall population levels remained comparatively low through the 1800s and early 1900s (Premier's Department 1951). 'Closer settlement' policies of the late 1800 s and early 1900s facilitated both the amalgamation of small properties and the subdivision of large runs. Amidst this flux, the regional settlement system that expanded from the railway and major roads that ran along the spine of the New England Tablelands was consolidated (Premier's Department 1951; Smailes \& Molyneux 1965; Atchison 1977).

Figure 2 shows the changing population levels of the New England \& North West SD - incorporating the Statistical Sub-Divisions of the New England Tablelands, the North Central Plain, and the North West Slopes - from 1961 to 2016. As is clear from this graph, the New England \& North West SD experienced sustained population growth (20\%, or $1 \%$ per annum) over the two decades from 1961 to 1981. The New England Tablelands' population growth exceeded that of the aggregate SD $(21.1 \%)$ while the drier, broadacre farming-dependent North Central Plain, incorporating Moree and 


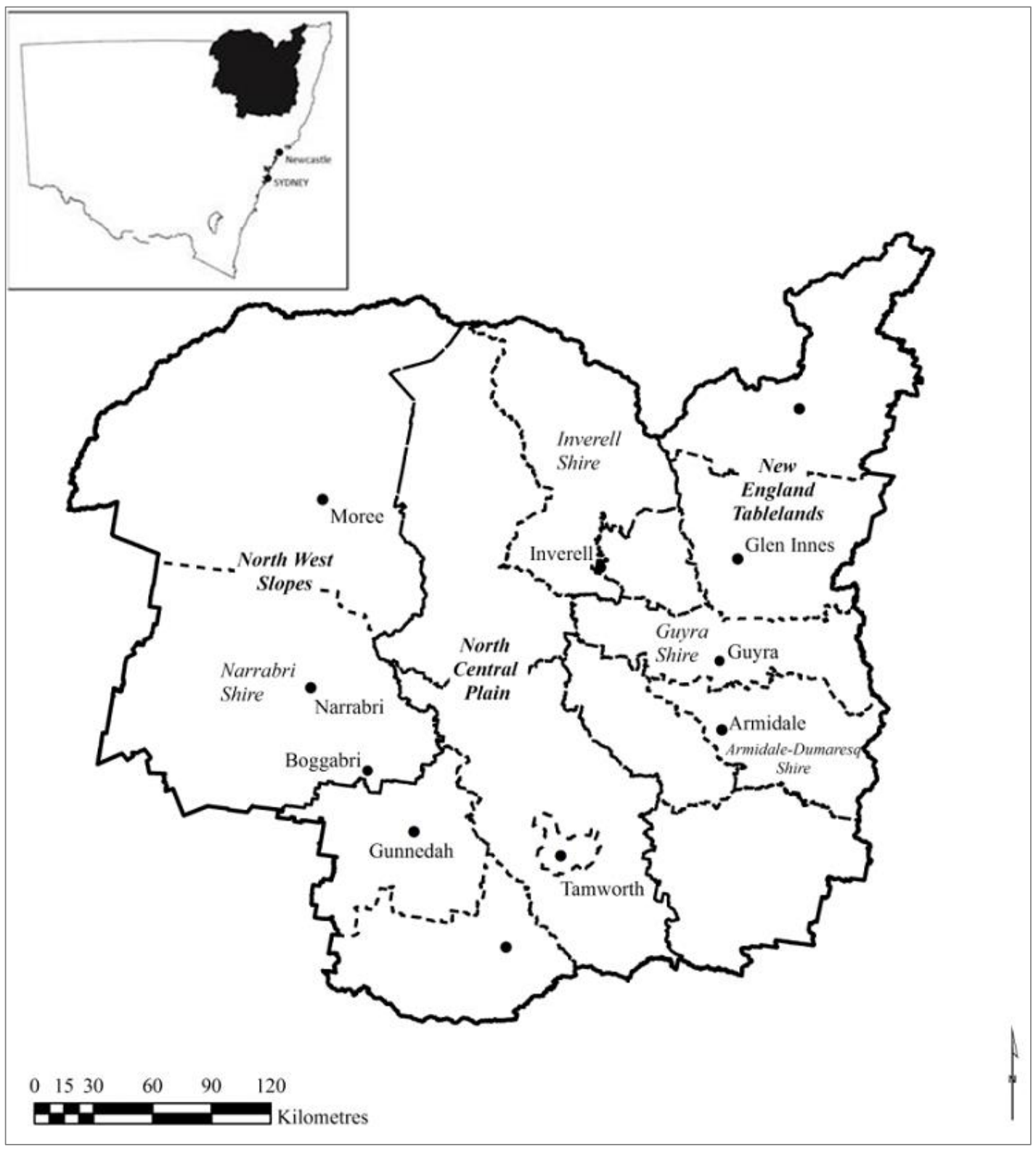

Figure 1: Map of New England \& North West Statistical Division, showing major sub-divisions Source: Argent (2016).

Narrabri, grew more slowly (14.5\%). Over the same period, each major region's population share shifted little: an approximate two percentage point decline for the North Central Plain was absorbed by its neighbour, the North West Slopes. Surprisingly, levels of urbanisation remained largely unchanged. In 1961, just over 65\% of the SD's population resided in towns or other urban centres; by 2011 this level had increased only slightly to $66.5 \%$. Throughout the $1980 \mathrm{~s}$ and $1990 \mathrm{~s}$, though, the New England \& North West SD experienced a period of slow, persistent population loss (see Table 1). For the remainder of this paper, I explore: (1) the spatial unevenness of demographic dynamics within the region since the 1990s; (2) the key demographic drivers of regional and sub-regional population change, including net decline; (3) the extent to which key drivers provide an indication of future demographic change; and, finally, (4) the extent to which these demographic indicators have manifested themselves differently for Indigenous and non-Indigenous populations within the region, to the extent that data permit. 


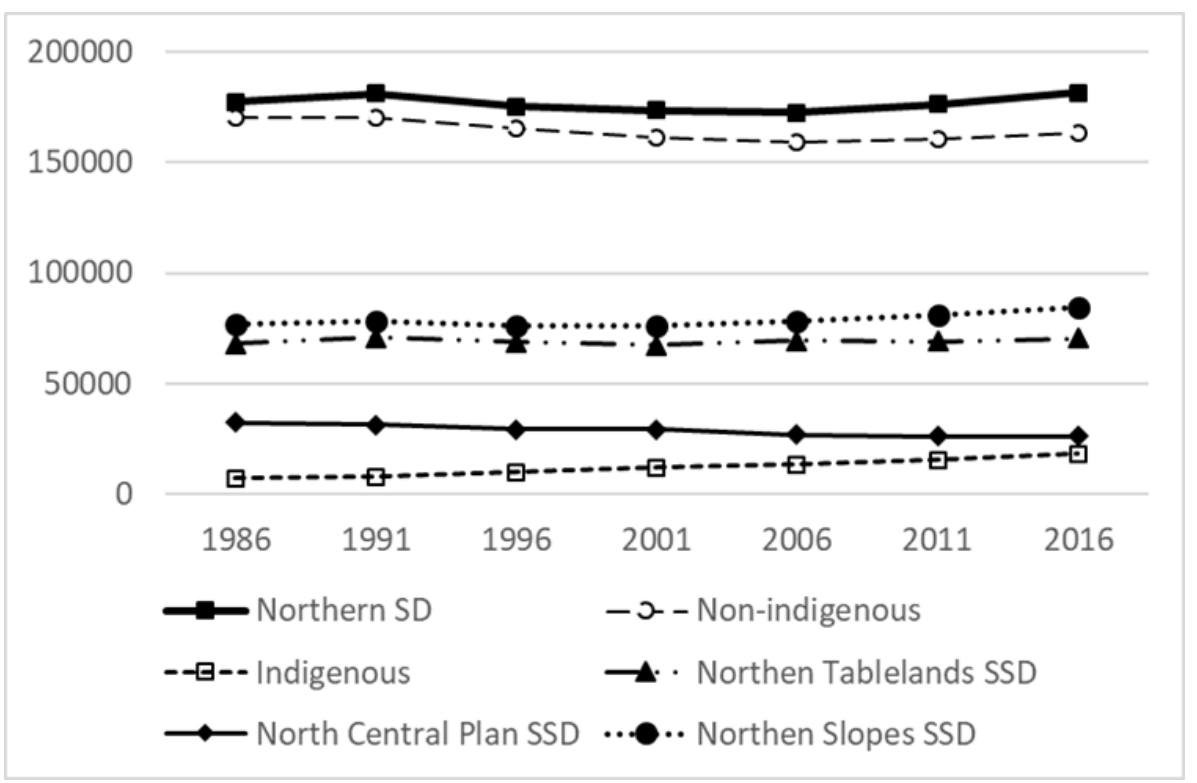

Figure 2: Population levels in New England \& North West SD and SSDs, 1986-2016 Source: Australian Bureau of Statistics, various censuses. Note: SSD = Statistical Subdivision.

Table 1: Indigenous and non-Indigenous population change, New England \& North West SD and SSDs, 1986-2016 (\% rate of change over period)

\begin{tabular}{lcccc}
\hline Regions/populations & $\mathbf{1 9 8 6 - 1 9 9 6}$ & $\mathbf{1 9 9 6 - 2 0 0 6}$ & $\mathbf{2 0 0 6 - 2 0 1 6}$ & $\mathbf{1 9 8 6 - 2 0 1 6}$ \\
\hline New England \& North West & $-1.2 \%$ & $-1.6 \%$ & $5.3 \%$ & $2.4 \%$ \\
Non-Indigenous & $-3.0 \%$ & $-3.8 \%$ & $2.7 \%$ & $-4.1 \%$ \\
Indigenous & $39.3 \%$ & $33.1 \%$ & $35.4 \%$ & $151.0 \%$ \\
\hline Northern Tablelands SSD & $0.9 \%$ & $1.0 \%$ & $1.7 \%$ & $3.6 \%$ \\
North Central Plan SSD & $-9.2 \%$ & $-8.5 \%$ & $-3.1 \%$ & $-19.4 \%$ \\
Northern Slopes SSD & $-0.3 \%$ & $2.0 \%$ & $8.8 \%$ & $10.7 \%$ \\
\hline
\end{tabular}

Source: Australian Bureau of Statistics, various censuses. Note: SSD = Statistical Subdivision.

\subsection{Disentangling different scales and trends in population change}

Figure 2 and Table 1 show that different sectors of the New England \& North West SD have experienced contrasting population trends since the mid-1980s, at least. The entire SD reached its hitherto population peak of about 181000 people at the 1991 Census, a level that it would not see again until a generation later. From the mid-1980s to the mid-1990s population loss was felt across almost the entire region but loss was concentrated particularly in the drier and more broadacre farming dependent North Central Plain. While individual towns and local government areas on the Tablelands and the Northern Slopes did experience decline during this period - smaller shires such as Barraba and Bingara losing over ten per cent of their residents between 1991 and 1996 - the overall population levels of these sub-regions exhibited slow growth over the entire three decades. Shires contiguous with the major regional centres of Armidale and Tamworth generally grew the fastest. However, the two westernmost local government areas of Moree and Narrabri underwent consistent depopulation over the thirty years from 1986, though the rate of loss did taper off in the decade prior to 2016. Between them, these two last-mentioned shires lost close to one-fifth of their populations over the study period. 
In many respects, then, the New England \& North West SD's last quarter century or so of fluctuating trends - first substantial decrease then slow but steady recovery - disguise some complex intra-regional processes. While net loss was consistently felt across all local government areas through the late 1980s and 1990s, the turn of the new century saw the eastern and southern portions of the SD - the Northern Tableland and the Northern Slopes - on the one hand, and the north-westernmost LGAs of Narrabri and Moree, on the other, diverge in their demographic trajectories. This emerging divide somewhat reflects the growing importance of the regional centres of Armidale, Inverell, Tamworth and Gunnedah relative to the smaller, more agriculturallydependent and lower amenity towns to the north and west. Further investigation of the dimensions of demographic divergence between the major regional centres and the smaller towns and rural remainder is not possible within the confines of this paper but would be a worthwhile exercise.

As discussed above, the SD is home to the Indigenous people of the Anaiwan and Kamillaroi nations (amongst others) as well as a non-Indigenous population of more recent provenance. For some decades it has been evident that Australia's Indigenous and non-Indigenous population are substantially different to each other in key demographic terms. While there has been some convergence noted between them over recent years in the areas of fertility and life expectancy (Carmichael 2019), Australia's Indigenous population exhibits a generally much younger age structure, is much more likely to live in rural and remote regions, and is growing substantially faster than the non-indigenous (Taylor 1997; Markham \& Biddle 2018; Taylor et al. 2020). As Table 1 and Figure 2 reveal, such stark contrasts between the two populations can also be discerned within the New England \& North West SD. A key aspect of Indigenous population growth, but one that is difficult to precisely quantify, relates to the relative propensity of people to identify as Indigenous; a tendency that varies spatially and temporally. As shown by Biddle \& Markham (2018), the national Indigenous population grew by around 80000 across the 2011-16 intercensal period due to this factor alone. Gains due to changes in identification have been strongest in more accessible parts of the country and negligible - at best - in remote regions (Taylor et al. 2020).

Between 1986 and 2016, while the SD population grew by close to 2.4 per cent in aggregate though noting the losses experienced through the 1980s and 1990s - the Indigenous population increased by just over 150 per cent (i.e., 5 per cent per annum). The non-indigenous population thus dropped by over four per cent overall for the same period. Although the Indigenous population still constitutes a relatively small minority within the SD its share of the population has more than doubled between 1986 and 2016, from just over four per cent to over ten per cent; though it comprises nearly 22 per cent of the Moree Plains LGA population. The reasons for this substantial proportional shift are difficult to pinpoint due to the unavailability of Indigenous fertility and mortality data at detailed spatial scales but, as is discussed in more detail below, a younger age structure, higher fertility and higher rates of natural increase should feature prominently in any explanation.

\subsection{Seven steps of rural population decline}

A diagnostic framework of impending population decline for New Zealand regions based on detailed demographic analysis was developed by Jackson (2014). Consisting of seven broad indicators that encompass the changing balance between mortality and fertility, and between 
young and old, Jackson's (2014) model demonstrates how shifts in age-sex structure over time can lead to natural decrease and almost irreversible population decline (see Table 2). For this paper, the full set of measures was applied to the Statistical Division for most of the study period (19962016), but only the first six indicators were used in the separate analyses of the Indigenous and non-Indigenous populations of the broad region and for a slightly shorter period due to unavailability of data (e.g., no Indigenous births and deaths data at the regional scale prior to 2001).

Table 2: Jackson's (2014) De-population Diagnostic Framework

\begin{tabular}{|c|c|}
\hline Indicator & Demographic measure \\
\hline Youth deficit & $15-24$ year old population $<15 \%$ of population \\
\hline \multirow[t]{2}{*}{ Labour market entry/exit ratio } & 15-24 / 55-64 age group ratio < national average \\
\hline & $15-24$ / 55-64 age group ratio $<1$ \\
\hline \multirow[t]{2}{*}{ Prime reproductive ages* } & Per cent $25-39$ age group $<$ national mean \\
\hline & Per cent $25-39$ age group $<15 \%$ of local population \\
\hline \multirow[t]{2}{*}{ Older population } & Per cent aged over $65>$ national mean \\
\hline & Per cent aged over $65>20 \%$ of local population \\
\hline \multirow[t]{2}{*}{ Prime working age } & Population aged 20-69 declining over time: numerically \\
\hline & Population aged 20-69 declining over time: proportionally \\
\hline \multirow[t]{2}{*}{ Older/youth ratio } & Ratio of over $65 \mathrm{~s} / 0-14$ year olds $>$ national mean \\
\hline & Ratio of over $65 \mathrm{~s} / 0-14$ year olds $>1$ \\
\hline Natural increase/decrease & Natural increase $<0.25 \%$ local population size \\
\hline
\end{tabular}

Source: Jackson (2014). * Note: For the Indigenous population, the prime reproductive age measure encompassed the 15-34 year age group given its different fertility behaviour (Carmichael 2019).

Table 3: Jackson's (2014) Diagnostic Framework applied to New England \& North-West SD and Australia

\begin{tabular}{llrrrrr}
\hline & & $\mathbf{1 9 9 6}$ & $\mathbf{2 0 0 1}$ & $\mathbf{2 0 0 6}$ & $\mathbf{2 0 1 1}$ & $\mathbf{2 0 1 6}$ \\
\hline Youth deficit & Australia & $14.4 \%$ & $13.7 \%$ & $13.6 \%$ & $13.3 \%$ & $12.8 \%$ \\
& New England \& N W & $13.7 \%$ & $13.1 \%$ & $12.8 \%$ & $12.7 \%$ & $12.2 \%$ \\
Entry/exit ratio & 1.73 & 1.46 & 1.23 & 1.15 & 1.09 \\
& Australia & 1.44 & 1.23 & 1.04 & 0.98 & 0.90 \\
Prime reproductive & Australia & $23.2 \%$ & $22.1 \%$ & $20.9 \%$ & $20.9 \%$ & $21.1 \%$ \\
& New England \& N W & $20.8 \%$ & $18.9 \%$ & $17.0 \%$ & $16.2 \%$ & $16.4 \%$ \\
\multirow{3}{*}{ \% aged 65+ } & Australia & $12.0 \%$ & $12.6 \%$ & $13.3 \%$ & $14.0 \%$ & $15.1 \%$ \\
& New England \& N W & $12.5 \%$ & $13.8 \%$ & $15.5 \%$ & $17.2 \%$ & $19.6 \%$ \\
Older/youth ratio working age & Australia & $62.5 \%$ & $63.0 \%$ & $63.8 \%$ & $64.5 \%$ & $64.6 \%$ \\
& New England \& N W & $60.6 \%$ & $60.3 \%$ & $60.5 \%$ & $60.5 \%$ & $60.5 \%$ \\
& Australia & 0.56 & 0.61 & 0.67 & 0.73 & 0.84 \\
\hline & New England \& N W & 0.53 & 0.61 & 0.72 & 0.83 & 1.00 \\
\hline
\end{tabular}

Source: Australian Bureau of Statistics, various censuses. Note: Shaded cells indicate results that exceed the indicator's threshold. 
Table 3 displays the results for six of the Jackson indicators applied to the nation as a whole and the New England \& North West SD. Of course, it needs to be recognised that regional age-sex structures are influenced, to a greater or lesser degree, by those of the broader nation, along with political, economic and social processes operating at national and other geographical scales. While the table does clearly demonstrate the gradual decline of the youthfulness of the SD and the concomitant impact of that change on other segments of the population it is important to recognise that Australia as a whole is also ageing and has been for some time. For instance, in relation to the youth deficit indicator, both Australia and the New England \& North West SD have fallen below the 15 per cent threshold since 1996 at least, though the size of the SD's deficit has expanded more rapidly than that of the nation. The workforce entry/exit ratio was well above 1.0 for both at the period's onset but has progressively declined over time and fallen below 1.0 (i.e., more people are notionally moving out of the workforce than entering) for the New England \& North West SD from around the time of the 2011 Census.

Not surprisingly, then, the proportion of the population in the post-retirement ages has increased at national and New England \& North West SD scales. Equally, the older/youth ratio has steadily grown from around one older person to every two youths in 1996 to 1.0 for the New England \& North West SD in 2016, and is approaching that level for Australia overall. The prime reproductive ages' proportional share of the population has shrunk slowly for the nation and the SD, though did jump slightly for both in 2016. Nonetheless, the New England \& North West's level is nearing the 15 per cent threshold for this indicator. Finally, the prime working age indicator has actually increased for the nation - possibly due to substantial international migrant intakes during the 2000s - while remaining largely unchanged for the SD. Overall, Table 3 shows that the SD's population has been more affected by ageing and other processes likely to lead to depopulation than the nation - another key dimension of Jackson's (2014) measures.

Needless to say, perhaps, migration has played a vital role in shaping population change and agesex structures across the New England \& North West SD (see Argent \& Walmsley 2008). Table 4 shows that natural increase has been maintained across the broad region since the turn of the current century, though natural decrease emerged in two LGAs (Glen Innes/Severn and Tenterfield), and nearly occurred in another (Gwydir) during the 2011-16 intercensal period. Such an outcome reflects declining fertility - itself an outcome of age-selective net migration loss which also helps drive the structural ageing dynamic within the region. As is obvious in the table, net out-migration was especially severe in the more remote, broadacre agriculture-dependent areas of Moree and Narrabri during the early 2000s. However, in terms of its implications for the youthfulness of local populations, and their capacity to replace themselves, net migration loss may have had the most substantial impacts on some of the more remote Tablelands and Slopes shires, such as Glen Innes/Severn, Tenterfield and Gwydir. 
Table 4: Natural change and net migration, New England \& North West SD, 2001-2016

\begin{tabular}{|c|c|c|c|c|c|c|}
\hline & $\begin{array}{l}\text { Natural } \\
\text { increase } \\
\text { (per 1000) }\end{array}$ & $\begin{array}{l}\text { Net } \\
\text { migration } \\
\text { rate } \\
\text { (per 1000) }\end{array}$ & $\begin{array}{l}\text { Natural } \\
\text { increase } \\
\text { (per 1000) }\end{array}$ & $\begin{array}{l}\text { Net } \\
\text { migration } \\
\text { rate } \\
\text { (per 1000) }\end{array}$ & $\begin{array}{l}\text { Natural } \\
\text { increase } \\
\text { (per 1000) }\end{array}$ & $\begin{array}{l}\text { Net } \\
\text { migration } \\
\text { rate } \\
\text { (per 1000) }\end{array}$ \\
\hline & \multicolumn{2}{|c|}{ 2001-06 } & \multicolumn{2}{|c|}{ 2006-11 } & \multicolumn{2}{|c|}{ 2011-16 } \\
\hline Northern Tablelands SSD & +17.83 & -20.82 & +18.72 & +6.93 & +14.04 & +6.99 \\
\hline North Central Plain SSD & +40.01 & -119.13 & +42.90 & -69.39 & +41.64 & -46.20 \\
\hline Northern Slopes SSD & +18.15 & +1.44 & +22.19 & +13.98 & +22.44 & +26.34 \\
\hline New England and N W & +21.73 & -27.66 & +24.08 & -1.86 & +22.02 & +8.35 \\
\hline
\end{tabular}

Source: Australian Bureau of Statistics, 2006, 2007, 2020a, 2020b. Note: SSD = Statistical Sub-Division.

To convey some sense of how ageing processes have affected different parts of the SD over time and space, Table 5 shows the results of applying the Jackson framework to the local government areas (LGAs) that comprise the New England \& North West SD, showing the proportion of LGAs whose population fell below each indicator. Working down the table, one can clearly see the relative decline of the youth and adolescent cohorts in the SD over the two decades. Almost all LGAs in the region have experienced a youth deficit for the entire period, and the workforce entry/exit ratio has rapidly fallen below 1.0 for all but one LGA by 2016, and was below the national mean for almost the full two decades. A further consequence of this shift for the region's age structure can be seen in the growing proportion of LGAs with over 20 per cent of their populations aged over 65 years and, on the same measure, which exceeded the national mean.

Table 5: Jackson's Framework applied to LGAs of New England \& North West SD, 1996-2016 (\% of LGAs that fell below the critical threshold for each indicator)

\begin{tabular}{lrrrrr}
\hline & $\mathbf{1 9 9 6}$ & $\mathbf{2 0 0 1}$ & $\mathbf{2 0 0 6}$ & $\mathbf{2 0 1 1}$ & $\mathbf{2 0 1 6}$ \\
\hline Youth deficit & $95 \%$ & $95 \%$ & $92 \%$ & $92 \%$ & $92 \%$ \\
Entry/exit ratio < & $37 \%$ & $58 \%$ & $75 \%$ & $75 \%$ & $92 \%$ \\
Entry/exit ratio < national level & $95 \%$ & $84 \%$ & $92 \%$ & $92 \%$ & $92 \%$ \\
Prime reproductive ages < 15\% & $0 \%$ & $0 \%$ & $8 \%$ & $50 \%$ & $42 \%$ \\
Prime reproductive ages < national mean & $95 \%$ & $95 \%$ & $92 \%$ & $100 \%$ & $100 \%$ \\
\% aged 65+ > 20\% & $0 \%$ & $11 \%$ & $0 \%$ & $42 \%$ & $58 \%$ \\
\% aged 65+ national mean & $63 \%$ & $79 \%$ & $83 \%$ & $100 \%$ & $100 \%$ \\
Older/youth ratio > 1 & $0 \%$ & $11 \%$ & $0 \%$ & $42 \%$ & $58 \%$ \\
Older/youth ratio > national mean & $53 \%$ & $68 \%$ & $67 \%$ & $83 \%$ & $92 \%$ \\
\hline Souce: Aus
\end{tabular}

Source: Australian Bureau of Statistics, 1998, 2007a, 2021.

The gradual temporal and spatial ageing of the regional population can be seen in the increasing proportion of LGAs whose older/youth ratio fell below 1 (from zero in 1996 to over half by 2016). Similarly, there has been a slow but sure expansion of the number of Shires whose 'reproductive ages' accounted for less than 15 per cent of their populations; from zero in 1996 and 2001 but up to around half by 2011. Such trends point to an almost inexorable decline in fertility in the region, itself obviously linked to the out-migration and net migration loss of young adults, as well as retirement-focused in-migration, which further accelerates local ageing and predisposed the regions to future natural decrease. 
Table 6 shows the same set of indicators applied to the New England \& North West SD's Indigenous population for the four Census years from 2001, while Table 7 does the same in relation to the region's non-Indigenous population (i.e., last mentioned is derived by subtracting the Indigenous population from the total population for the SD for each indicator). The Indigenous population presents a striking contrast to the non-Indigenous population across virtually all measures; the proportion of its population that is deemed young is growing rather than declining, and the same is true for the prime working age population. While the workforce entry/exit ratio has declined it has done so from a relatively high level, and is still over double that of the nation. On all other indicators the SD's Indigenous population easily exceeds the Jackson indicator thresholds, although some slow convergence is occurring between the Indigenous and nonIndigenous populations in this regard. Notwithstanding its minority status in the region the Indigenous population is a source of rejuvenation. This point is borne out by Table 7 which shows that the youth deficit would have been more severe, and the workforce entry/exit ratios and youth/aged ratios would have been lower, and would have fallen below the critical thresholds earlier, if not for the Indigenous population.

Table 6: Jackson's Framework applied to the New England \& North West SD Indigenous population

\begin{tabular}{lrrrr}
\hline & $\mathbf{2 0 0 1}$ & $\mathbf{2 0 0 6}$ & $\mathbf{2 0 1 1}$ & $\mathbf{2 0 1 6}$ \\
\hline Youth deficit & $17.9 \%$ & $17.9 \%$ & $18.5 \%$ & $18.1 \%$ \\
Entry/exit ratio < & 3.73 & 3.26 & 2.95 & 2.31 \\
Entry/exit ratio < national level & Yes & Yes & Yes & Yes \\
Prime reproductive ages $<15 \%$ & $31.5 \%$ & $29.7 \%$ & $29.8 \%$ & $29.8 \%$ \\
Prime reproductive ages < national mean & No & No & No & No \\
\% aged 65+ > 20\% & $2.9 \%$ & $3.5 \%$ & $4.5 \%$ & $6.0 \%$ \\
\% aged 65+ $>$ national mean & No & No & No & No \\
Prime working age & $49.0 \%$ & $49.5 \%$ & $51.3 \%$ & $53.9 \%$ \\
Older/youth ratio > 1 & 0.07 & 0.09 & 0.12 & 0.17 \\
Older/youth ratio > national mean & No & No & No & No \\
\hline Souce Austran
\end{tabular}

Source: Australian Bureau of Statistics (1998, 2007a, 2021)

Table 7: Jackson's Framework applied to the New England \& North West SD non-Indigenous population

\begin{tabular}{lrrrrr}
\hline & $\mathbf{2 0 0 1}$ & $\mathbf{2 0 0 6}$ & $\mathbf{2 0 1 1}$ & $\mathbf{2 0 1 6}$ \\
\hline Youth deficit & $12.8 \%$ & $12.4 \%$ & $12.2 \%$ & $11.5 \%$ \\
Entry/exit ratio $<1$ & 1.15 & 0.96 & 0.89 & 0.82 \\
Prime reproductive ages $<15 \%$ & $18.8 \%$ & $16.9 \%$ & $16.2 \%$ & $16.4 \%$ \\
\% aged 65+ $>$ 20\% & $14.6 \%$ & $16.5 \%$ & $18.4 \%$ & $20.9 \%$ \\
Prime working age & $61.1 \%$ & $61.5 \%$ & $61.4 \%$ & $61.3 \%$ \\
Older/youth ratio $>1$ & 0.69 & 0.83 & 0.97 & 1.18 \\
\hline
\end{tabular}

Source: Australian Bureau of Statistics (1998, 2007a, 2021). 


\section{Conclusions}

In the context of the major ideological and regulatory shifts that took place in rural Australia from the 1970s, along with occasional if severe climatic conditions (e.g., protracted droughts), this paper sought to explore some of the key factors that underlay its spatially and temporally uneven experiences of population decline through the 1990s and 2000s. In addition, but perhaps even more importantly, it has investigated some of the diverse trajectories of demographic change across the New England \& North West SD over the past thirty years, taking into account indigeneity and relative location. Unfortunately, and this is a weakness of the paper's overall argument, data on Indigenous fertility and mortality are unavailable at the local scale and this has precluded the measurement of natural increase/decrease and net migration in the same manner as for the non-Indigenous population.

In applying Jackson's (2014) diagnostic framework to the region as a whole, the analysis has revealed how ageing processes in combination with age-selective migration has affected the age structure, and eventually the capacity of individual LGAs to, for example, replace retiring workers and experience natural increase. A profound ageing process is underway across the entire region and is becoming more severe with the passing years. However, the SD's Indigenous population presents a striking contrast to the non-Indigenous one, growing rapidly, increasing its share of the population particularly in the western-most LGAs - and is a force for demographic rejuvenation, and boosting local school enrolments, the demand for post-school training and education and workforce entry rates. However, the continued heavy migration losses in the same regions where nature increase is highest suggest that a lack of employment and social opportunities, together with changing environmental factors, perhaps (e.g., droughts, heatwaves), are forcing residents to seek their fortunes elsewhere. Nonetheless, it is vital for future demographic planning for rural regions that greater attention is paid to this trend by academics and policy-makers.

\section{Key messages}

- Structural population ageing is affecting the demographic trajectories of the broad rural region of the New England \& North-West SD of New South Wales, leading to eventual natural decrease in some local government areas.

- Net migration loss has been particularly severe in the most remote and agriculturally-dependent parts of the SD.

- Experiences of population decline through the 1990s and 2000s were felt unevenly throughout the SD.

- The Indigenous population of the SD has grown rapidly over the thirty years to 2016 , and more than doubled its share of the population, particularly in the youth and young adult age groups where the demand for schooling and labour market entry support is greatest.

\section{Acknowledgments}

The author thanks the reviewer for their incisive and constructive comments on an earlier draft of this paper. All remaining errors and omissions are those of the author alone. 


\section{References}

ABARES (Australian Bureau of Agricultural and Resource Economics and Sciences) (2015) Agriculture and forestry in the New England and North West region of New South Wales, 2015. https://www.awe.gov.au/abares/research-topics/aboutmyregion/nsw-new-england

ABS (1998) Regional statistics - New South Wales, Commonwealth of Australia.

ABS (2006) Deaths, Australia, 2006, cat. No. 3302.0, Commonwealth of Australia.

ABS (2007a) 2001 Census Community Profile Series: Time Series Profile: Commonwealth of Australia.

ABS (2007b) Births, Australia, 2006, cat. No. 3301.0, Commonwealth of Australia.

ABS (2020a) Births, Australia, 2019, cat. No. 3301.0, Commonwealth of Australia.

ABS (2020b) Deaths, Australia, 2019, cat. No. 3302.0, Commonwealth of Australia.

ABS (2021) Age x sex for select New South Wales local government areas, 2016 Census, Census Tablebuilder. Accessed 15 July 2021.

Argent N \& Walmsley D (2008) Rural youth migration trends in Australia: An overview of recent trends and two inland case studies. Geographical Research 46(2): 139-152. https://doi.org/10.1111/i.1745-5871.2008.00505.x

Argent N (2002) From Pillar to Post? In search of the post-productivist countryside in Australia. Australian Geographer 33(1): 97-114. https://doi.org/10.1080/00049180220125033

Argent N (2016) Australia: Trap or opportunity? Natural resource dependence, scale, and the evolution of new economies in the space/time of New South Wales' Northern Tablelands. In Halseth G. (Ed.) Transformation of resource towns and peripheries: Political economy perspectives. Routledge; pp. 18-50.

Argent N (2016) Demographic change: beyond the urban-rural divide. In Shucksmith M \& Brown D (Eds.) Routledge International Handbook of Rural Studies. Routledge; pp. 29-35.

Argent N, Smailes P, \& Griffin T (2007) The Amenity Complex: towards a framework for analysing and predicting the emergence of a multifunctional countryside in Australia. Geographical Research 45(3): 217-232. https://doi.org/10.1111/j.1745-5871.2007.00456.x

Argent N, Walmsley D, \& Sorensen A (2010) Something old, something new, something borrowed, something .....? Rediscovering the comparative advantage of the 'new' pastoral economies of northern New South Wales, Australia. In Halseth G, Markey S and Bruce D (Eds.) The Next Rural Economies: Constructing Rural Place in Global Economies. CABI Publishing; pp. 17-31.

Atchison J (1977) The evolution of settlement. In Lea D, Pigram J, \& Greenwood L (Eds.) An Atlas of New England, Vol. 2 - The Commentaries. Department of Geography, University of New England; pp. 171-181.

Beale C (1975) The revival of rural population growth in non-metropolitan America, ERS Report 605. Washington, DC: USDA-Economic Research Service.

Biddle N \& Markham F (2018) Indigenous identification change between 2011 and 2016: Evidence from the Australian Census longitudinal Dataset. CAEPR topical Issue No. 1/2018, ANU. https://caepr.cass.anu.edu.au/research/publications/indigenous-identification-change-between2011-and-2016-evidence-australian

Brown D \& Argent N (2016) The impacts of population change on society and environment. In Shucksmith M \& Brown D (Eds.) Routledge International Handbook of Rural Studies. Routledge; pp. 85-95.

Bryant C \& Joseph A (2001) Canada's rural population: trends in space and implications in place. Canadian Geographer 45(1): 132-137. https://doi.org/10.1111/j.1541-0064.2001.tb01177.x

Burnley I \& Murphy P (2004) Sea Change: Movement from Metropolitan to Arcadian Australia. UNSW Press.

Carmichael G (2019) Indigenous fertility in Australia: updating Alan Gray. Journal of Population Research 36(4): 283-317. https://doi.org/10.1007/s12546-019-09233-w 
Cawley M (1994) Desertification: measuring population decline in rural Ireland. Journal of Rural Studies 10(4): 395-407. https://doi.org/10.1016/0743-0167(94)90049-3

Dax T \& Fischer M (2018) An alternative policy approach to rural development in regions facing population decline. European Planning Studies 26(2): 297-315. https://doi.org/10.1080/09654313.2017.1361596

Gray I \& Lawrence G (2001) A Future for Regional Australia. Cambridge University Press.

Holmes J (2006) Impulses towards a multifunctional transition in rural Australia: gaps in the research agenda. Journal of Rural Studies 22(2): 142-160. https://doi.org/10.1016/j.jrurstud.2005.08.006

Hugo G (1994) The turnaround in Australia: Some first observations from the 1991 Census. Australian Geographer 25(1): 1-17. https://doi.org/10.1080/00049189408703094

Ilbery B \& Bowler I (1998) From agricultural productivism to post-productivism. In Ilbery B (Ed.) The Geography of Rural Change. Addison Wesley Longman; pp. 57-84.

Jackson N (2014) Sub-national depopulation in search of a theory - towards a diagnostic framework. New Zealand Population Review 40: 3-39. https://population.org.nz/app/uploads/2015/07/NZPR-Vol40- Jackson.pdf

Lowe P \& Ward N (2009) England's rural futures: a socio-geographical approach to scenarios analysis. Regional Studies 43(10): 1319-1332. https://doi.org/10.1080/00343400903365169

Markham F \& Biddle N (2018) Recent changes to the Indigenous population geography of Australia: evidence from the 2016 Census. Australian Population Studies 2(1): 1-13. https://doi.org/10.37970/aps.v2i1.21

Nelson P B (2001) Rural restructuring in the American West: land use, family and class discourses. Journal of Rural Studies 17(4): 395-407. https://doi.org/10.1016/S0743-0167(01)00002-X

Premier's Department (1951) The New England region: A preliminary survey of resources. Sydney: Government of New South Wales.

Pritchard B \& McManus P (Eds.) (2000) Land of Discontent. UNSW Press.

Ramsey D (2010) Rural restructuring and the new rural economy: examples from Germany and Canada. In Halseth G, Markey S, \& Bruce D (Eds.) The Next Rural Economies. Constructing Rural Place in Global Economies. CABI; pp. 115-127.

Smailes P \& Molyneux J (1965) The evolution of an Australian rural settlement pattern: Southern New England, NSW. Transactions of the Institute of British Geographers 36: 31-54. https://doi.org/10.2307/621452

Smailes P, Griffin T, \& Argent N (2019) Regional Cities and City Regions in Rural Australia. Springer. https://doi.org/10.1007/978-981-13-1111-6

Sorensen A (1990) Virtuous cycles of growth and vicious cycles of decline: regional economic change in Northern NSW. In Walmsley D (Ed.) Change and Adjustment in Northern NSW. Department of Geography and Planning, University of New England; pp. 41-59.

Taylor A, Wilson T, Temple J, Kelaher M, \& Eades S (2020) The future growth and spatial shift of Australia's Aboriginal and Torres Strait Islander population, 2016-2051. Population, Space and Place https://doi.org/10.1002/psp.2401

Taylor J (1997) The contemporary demography of the Indigenous Australians. Journal of the Australian Population Association 14: 77-114. https://doi.org/10.1007/BF03029488

United Nations (2012) Urban and Rural Areas, 2011. UN Population Division.

Williams M (1975) More and smaller is better: Australian rural settlement 1788-1914. In Powell J \& Williams M (Eds.) Australian Space/Australian Time: Geographical Perspectives. Oxford University Press; pp. 61-103. 
Wilson G (2001) From productivism to post-productivism ... and back again? Exploring the (un)changed natural and mental landscapes of European agriculture. Transactions of the Institute of British Geographers 26(1): 77-102. https://doi.org/10.1111/1475-5661.00007

Zelinsky W (1971) The Hypothesis of the mobility transition. Geographical Review 61(2): 219-249. https://doi.org/10.2307/213996 